\title{
Cinco décadas de transformaciones en La Araucanía Rural
}

\author{
Luis Henríquez Jaramillo
}

Universidad de La Frontera, Temuco, Chile. Email: luishenriquez-j@ufro.cl

\begin{abstract}
Resumen: La Araucanía tiene una población rural que alcanza al 31\% del total, lo que la convierte en una de las regiones con mayor ruralidad del país. Así mismo, La Araucanía es el referente histórico y territorial del pueblo mapuche, cuya población alcanza al 23,4\% del total regional, de la cual el 70\% son habitantes rurales. La Araucanía en las últimas cinco décadas ha experimentado profundas transformaciones derivadas de la aplicación de diversos modelos político-económicos y sus respectivas políticas públicas, que han afectado al mundo rural. Estas políticas públicas incluyen un proceso de reforma agraria, contrarreforma agraria, división de la propiedad mapuche, instalación de una economía abierta, fomento forestal de plantaciones artificiales y la promulgación de una nueva ley indígena, entre otras. Este artículo pretende identificar y hacer una revisión de las principales políticas y sus consecuencias, con el propósito de sugerir orientaciones para elaborar programas públicos pertinentes.
\end{abstract}

Palabras clave: ruralidad, Araucanía, políticas públicas, cambios.

\section{Five decades of transformations in Araucanía Rural}

\begin{abstract}
The Araucanía has a rural population that reaches 31\% of the total, making it one of the regions in the country with the largest rurality. Likewise, the Araucanía is the historical and territorial reference of the Mapuche people, whose population amounts to $23.4 \%$ of the regional totality, of which $70 \%$ are rural dwellers. The Araucanía, in the past five decades, has undergone various transformations resulting from different political-economic models and their respective policies, which have affected the rural world. These policies include a process of land reform, land counterreform, Mapuche property division, the installation of an open economy, forestry promotion of artificial plantations, and the enactment of a new indian law, among others. This article seeks to identify and review of major policies and their consequences, in order to suggest guidelines for developing relevant public programs.
\end{abstract}

Key words: rurality, Araucanía, public policies, changes.

\section{Cinco décadas de transformações em Araucanía Rural}

Resumo: O Araucanía tem uma população rural que atinge 31\% do total, tornando-se uma das maiores ruralidades das regiões do país. Da mesma forma, La Araucanía é a referência histórica e territorial do povo Mapuche, cuja população equivale a $23,4 \%$ do total regional, dos quais $70 \%$ são moradores rurais. O Araucanía nas últimas cinco décadas tem sofrido profundas alterações decorrentes da implementação de diversos modelos político-econômicos e suas respectivas políticas públicas que têm afectado o mundo rural. Essas políticas incluem um processo de reforma agrária, contra-reforma agrária, a divisão da propriedade Mapuche, a 
instalação de uma economia aberta, fomento de plantação artificial e promulgação de uma nova lei indígena, entre outros. Este artigo procura identificar e analisar as políticas principais e suas conseqüências, a fim de sugerir diretrizes para o desenvolvimento de programas públicos relevantes.

Palavras-chave: ruralidade, Araucanía, mudanças de políticas públicas.

$* * *$

\section{Introducción}

La actual Región de La Araucanía se integró plenamente al Estado nacional -mediante la ocupación militar- setenta años después del nacimiento de Chile como república independiente. Desde sus inicios su vocación productiva fue la silvoagropecuaria, generándose una estructura agraria que mantuvo la hacienda como eje (Bauer 1994). Sin embargo, presentó diferencias con la estructura agraria de la zona central de Chile al originarse una pequeña agricultura indígena y no indígena producto de los procesos de radicación y colonización (Rivera 1988).

Durante el periodo de post-ocupación comprendido entre 1883 y 1930, La Araucanía desarrolló una economía donde la producción triguera sería el pilar más importante, pero también alcanzan un rol muy significativo la ganadería y la actividad forestal, la que se hace cada vez más trascendental en la medida que avanza el siglo XX. Los grandes productores se vincularon a la economía nacional e internacional, y con el tiempo fueron desarrollando una mayor especialización productiva (Flores 2006). Por su parte, los medianos y pequeños productores, colonos extranjeros, chilenos y mapuches, conformaron un mercado económico regional y local, tanto en intercambios de bienes como de mano de obra, en un status de inferioridad en la relaciones de mercado con lo cual transferían excedentes a las posiciones de mayor poder, dando origen a una economía con grados de complejidad (Ibíd.).

Desde 1900 a 1930 la economía regional presenta un ciclo expansivo, época donde se constituye en el "granero de Chile". Posteriormente, entre 1930 y 1960, este auge seguido por un ciclo de contracción económica (Pinto y Ordenes 2012).

Esta pequeña agricultura indígena y no indígena, se incorporó tempranamente al modelo de acumulación de La Araucanía, jugando un rol subordinado hasta la década de 1960, época en que los procesos sociales, políticos y económicos nacionales e internacionales dan origen a la reforma agraria chilena en el cual los campesinos y la pequeña agricultura juegan un papel muy relevante.

Con posterioridad al Golpe Militar de 1973 se verifica una liquidación forzada del proceso de reforma agraria y la instalación de la contrarreforma agraria que no restituye la hacienda, sino que abre paso a una agricultura de corte empresarial moderna. Una agricultura que de un contexto de economía protegida, en un corto lapso de tiempo pasa a enfrentar una apertura económica radical que genera grandes impactos en el sector, en particular en los cultivos tradicionales, base de la producción de la agricultura familiar, los que paulatinamente son reemplazados por plantaciones forestales y en menor medida por cultivos orientados a la exportación e industrialización.

Este proceso de modernización económico productiva no ha sido capaz de resolver los problemas de equidad y, por el contrario, a menudo generó conflictos 
sociales y ambientales. En efecto, la transformación económica iniciada en los años ochenta sólo significó progreso para aquellos espacios y grupos que lograron articularse a nuevos mercados, pero la lógica espacial del modelo generó nuevos desequilibrios territoriales intrarregionales (Gobierno Regional de La Araucanía 2009).

En tanto, el movimiento campesino que hasta el año 1973 había tenido un gran desarrollo, es perseguido, decae y sin apoyo del Estado languidece y es reemplazado por el movimiento mapuche como actor social principal.

En efecto, el movimiento mapuche se reorganiza a partir de la dictación de los D. L. 2568 y 2750 de 1979 que buscaron acelerar el proceso de división de las comunidades. Desde ese momento fue alcanzando crecientes grados de movilización y de complejización en sus demandas y reivindicaciones, sociales, culturales, territoriales y políticas, logrando primero la dictación de la Ley Indígena N 19.253 y, más recientemente, la ratificación del Convenio 169 de la OIT, proceso que ha generado un marco político jurídico exigente para las relaciones interculturales.

A partir de fines de los ochenta la re-democratización del país, sus regiones y municipios, trajo como consecuencia el establecimiento de programas sociales e inversiones en infraestructura social y económica que se han traducido en innegables progresos para La Araucanía y sus habitantes rurales. Así, es posible ver que el $96 \%$ de la población rural tiene energía eléctrica en sus hogares, la totalidad de las ciudades cabeceras comunales tiene acceso mediante caminos pavimentados y la pobreza rural cayó de un 45.4\% el año 1990 a un 19,9\% el 2006.

Por otro lado, desde el Estado chileno se ha venido desarrollando un lento y débil proceso de descentralización, creando los gobiernos regionales el año 1992, modificando el Fondo Nacional de Desarrollo Regional (FNDR) el 2005 y, finalmente, transfiriendo las competencias de planificación y ordenamiento territorial a los gobiernos regionales, herramientas que han sido claramente insuficientes para enfrentar los desafíos.

Resumidamente, podemos afirmar que la sociedad rural de La Araucanía en las últimas cinco décadas ha sufrido profundas transformaciones, algunas de ellas son coincidentes con cambios experimentados en la ruralidad latinoamericana (Kay 1995), otras tienen características propias. Estas transformaciones -que en general han sido de gran velocidad y radicalidad- son consecuencia de los dispares experimentos económicos y políticos del que Chile ha sido objeto y que aparentemente éstas parecen no detenerse. Este escenario tan cambiante impone desafíos conceptuales y prácticos a los líderes sociales, dirigentes políticos, miembros del ejecutivo y diseñadores de políticas públicas.

En este trabajo pasaremos revista a algunas de las principales políticas públicas, sus alcances y consecuencias en el ámbito rural, desde una perspectiva del desarrollo sustentable, con el objeto de identificar futuros temas de investigación aplicada y entregar elementos de juicio a los tomadores de decisión.

\section{Reforma agraria y contrarreforma agraria en La Araucanía}

A partir del año 1962, durante el Gobierno de Jorge Alessandri Rodríguez, se inicia el proceso de reforma agraria con la dictación, en noviembre de ese año, de la Ley $\mathrm{N}^{\circ}$ 15.502, cuerpo legal que en La Araucanía y bajo el mencionado 
mandato no tuvo un mayor alcance. En efecto, solo se registra la entrega de sitios por una superficie de 9 hectáreas en las zonas IX y X regiones, de las cuales formaban parte las provincias de Malleco y Cautín (Garrido, Guerrero y Valdez 1988).

En el gobierno del Presidente Eduardo Frei Montalva, durante los tres primeros años de su administración, siguió aplicándose la Ley $\mathrm{N}^{\circ} 15.502$ y bajo su vigencia en la región se expropiaron 50 predios por una superficie de 34.012 hectáreas. En tanto a nivel nacional significó la expropiación de 472 predios, con una superficie total de más de 1.200.000 hectáreas (Correa, Molina y Yáñez 2005).

Durante el Gobierno de Eduardo Frei Montalva se dicta la segunda ley de reforma agraria, la $\mathrm{N}^{\mathrm{0}} 16.640$ de 1967 , la que fue acompañada de leyes anexas como las $\mathrm{N}^{\mathrm{o}} 16.4765$ y $\mathrm{N}^{\circ} 6.615$, esta última reforma constitucional, que permitieron mejorar la capacidad del Estado para llevar adelante el proceso expropiatorio, lo que se tradujo en un aumento en el número de expropiaciones y un incremento en la velocidad del proceso.

La reforma agraria, desarrollada por los distintos gobiernos, no tenía como objetivo específico favorecer la recuperación de tierras mapuches, indígenas "bajo ningún aspecto favoreció al pueblo mapuche, constituyó más bien una imposición racionalista centrada en lo económico, que pretendía hacer más eficiente y productiva la agricultura chilena, no considerando en ningún momento a la tierra como fuente creencial y un elemento de reproducción cultura” (Zúñiga 1997).

Durante el gobierno de la Unidad Popular, se propone profundizar lo realizado en los gobiernos anteriores. En La Araucanía los campesinos de origen mapuche se organizan y generan un proceso de movilizaciones sociales muy marcado que consistió básicamente en la ocupación o "toma” de fundos y corridas de cerco con el objeto de recuperar tierras que reclamaban como propias y alegaban habían sido usurpadas. Esto porque consideraban que el proceso de reforma agraria no consideraba sus demandas y reivindicaciones. Esta serie de movilizaciones de recuperación de tierras, denominadas el "Cautinazo", tuvieron su punto más álgido en los meses de enero y febrero de 1971.

Es preciso indicar que las movilizaciones superaban el marco de la ley y en muchos casos existió discrecionalidad respecto de los predios a expropiar, como también en la asignación de las reservas a las que tenían derecho los empresarios expropiados. Estas prácticas causaron profundo malestar y resentimiento en el sector empresarial y sus organizaciones representativas, lo que quedó latamente registrado en la prensa de la época (Ibíd.).

El proceso de reforma agraria en la Región de La Araucanía presentó una gran magnitud y alta conflictividad. Expresado en término numéricos, significó la expropiación de 688 predios que sumaban 739.245 hectáreas (Correa, Molina y Yáñez 2005). Por su parte EULA (2003) indica que la superficie total efectivamente expropiada alcanzó las 763.056 hectáreas, esto es, aproximadamente un $30 \%$ de la superficie silvoagropecuaria regional. Sin embargo, las tierras finalmente asignadas alcanzaron solamente a 219.930 hectáreas (Ibíd.), lo que también demuestra la magnitud del proceso de normalización y contrarreforma agraria.

Este proceso de contrarreforma agraria se inició “ya al día siguiente del Golpe Militar de 1973 con los decretos leyes que detuvieron las expropiaciones de la tierra de la Corporación de Reforma Agraria (CORA) y los que establecieron la devolución de aquellas tierras, aun no legalmente expropiadas, a 
sus anteriores dueños. Esto remató con el Decreto Ley $\mathrm{N}^{\circ} 2.247$, dictado en 1978, que modificó la Ley N 16.640 de Reforma Agraria y en 1979 se publica el Decreto Ley que liquida la propia Corporación de Reforma Agraria” (Berdichewsky 1983: 279).

Paralelo a la contrarreforma agraria se vivió un proceso de supresión de las organizaciones campesinas y la persecución de sus dirigentes. En efecto, después del Golpe de Estado se verifican 177 detenidos y ejecutados políticos en La Araucanía, de los cuales un gran contingente eran campesinos mapuches y no mapuches (CESOC-UCT 2001). Las víctimas de origen rural fueron mayoritariamente reprimidas por haber participado del proceso de reforma agraria como asentados o dirigentes.

La magnitud y radicalidad de los procesos de reforma y contrarreforma agraria generaron profundas consecuencias en términos de marginación de amplios sectores de familias campesinas mapuches y no mapuches, demandas pendientes, abandono y persecución. Pero también resentimiento por parte de los agricultores empresariales que se sintieron abusados.

\section{La división de las tierras mapuches}

A fines de los años setenta el nuevo modelo de país de propietarios individuales es intentado imponer al pueblo mapuche a través de los decretos leyes Nos. 2.568 y 2.750 de 1979 que pretenden abrir las tierras mapuches al sistema común de propiedad, obligando en la práctica a la subdivisión de las comunidades. Para ello esta legislación, en su artículo número 10, faculta a cualquier ocupante de la comunidad indígena, sea éste mapuche o no, para solicitar la división de la comunidad. Este procedimiento además fue expedito y gratuito (Aylwin y Castillo 1990).

Es importante resaltar que el Decreto Ley $N^{\circ} 2.568$ presentaba una marcada orientación etnocida. En efecto, este decreto contenía un párrafo en su artículo primero que señalaba "a partir de la fecha de su inscripción en el Registro de Propiedad del Conservador de Bienes Raíces, las hijuelas resultantes de la división de las reservas, dejarán de considerarse tierras indígenas, e indígenas a sus dueños o adjudicatarios”.

La oposición decidida del campesinado mapuche y el respaldo que obtuvo de la Iglesia Católica desde el primer momento, obligaron a la dictación de un decreto modificatorio (D. L. N $\mathrm{N}^{\circ} 2.750$ de julio de 1979) donde se modificó el párrafo antes mencionado, pero manteniendo su propósito original.

En base a esta legislación, elaborada sin participación alguna del pueblo mapuche, entre 1979 y marzo del 1990 la Dirección de Asuntos Indígenas de INDAP -organismo encargado de realizar este proceso de división de comunidades-, había otorgado 72.068 títulos de dominio a indígenas con una superficie total de 463.409 hectáreas (Ibíd.), lo que en la práctica, terminó con la casi totalidad de las comunidades reduccionales mapuches creadas tras la anexión forzada de La Araucanía.

Si bien dicha legislación prohibió la enajenación de las hijuelas resultantes de la división, muchas tierras mapuches fueron traspasadas a no indígenas a través de contratos fraudulentos, como los arriendos hasta por 99 años, que son parte de las reivindicaciones de tierra que actualmente las organizaciones mapuches plantean. 
Por otro lado, para los efectos del análisis que venimos haciendo, digamos que los decretos leyes mencionados en los párrafos precedentes, establecieron lo que se llamó "el derecho de ausente", en virtud del cual los mapuches que no estaban en las tierras comunitarias, cuando se iniciaba la división de la comunidad, automáticamente perdían todo derecho a la tierra, en que se les declaraba ausentes, recibiendo, de esa manera, tierras sólo el comunero que estaba en el lugar. Con este procedimiento, muchas personas, que por diversas razones habían emigrado a las ciudades o fuera del país probablemente en busca de mejores oportunidades, perdieron su derecho a la tierra, es decir, el derecho a la herencia que le correspondía en la comunidad.

Cabe mencionar que a cambio este derecho se le cancelaría en dinero conforme al avalúo fiscal que tuvieran las tierras de la comunidad, según señala el D. L. $\mathrm{N}^{\circ}$ 2.568, en su párrafo tercero, de la liquidación de las comunidades, específicamente en los artículos 28 al 31.

Esta verdadera confiscación del derecho a la herencia se hizo, no obstante, estar vigente el Acta Constitucional $\mathrm{N}^{\circ} 3$ en que se establecía y protegía el sagrado derecho a la propiedad privada de todos los habitantes del país sin distinción alguna. Resulta paradojal que aquellos que criticaron tan fuertemente la reforma agraria porque se había conculcado el derecho de propiedad, no tuvieran reparos en hacerlo con un grupo social que en ese momento en Chile contaba con escaso poder. A muchos ciudadanos mapuches el Estado les pagó por su derecho de ausentes valores francamente irrisorios (Huenchumilla 2002).

Si bien es cierto según la Ley Indígena $N^{\circ} 19.253$ la CONADI heredó la responsabilidad de regularizar esta situación, se mantuvieron los criterios anteriores y, finalmente, el Consejo de la CONADI decidió suspender este proceso porque era una vergüenza pagarles esas sumas a las personas declaradas ausentes. El año 2002, unos 20.000 mapuches esperaban que algún día el Estado les pagara sus derechos y el problema subsiste hasta el día de hoy (Ibíd.).

Sin embargo, la dictación de los decretos leyes Nos. 2.568 y 2.750 provocó la rearticulación y reemergencia del movimiento mapuche que se oponía a esta medida y, si bien es cierto los dirigentes mapuches no lograron detener el proceso de división, sentaron las bases para la reactivación de las organizaciones mapuches. En efecto, a partir de allí el movimiento social mapuche fue alcanzando crecientes grados de movilización y de complejización en sus demandas y reivindicaciones, sociales, culturales, territoriales y políticas, logrando -junto a los otros pueblos originarios de Chile- primero la dictación de la Ley Indígena $\mathrm{N}^{\circ} 19.253$ y, más recientemente, la ratificación del Convenio 169 de la OIT, proceso que ha generado un marco político jurídico más exigente para las relaciones entre los pueblos indígenas y el Estado chileno.

\section{La política de tierras de la Ley Indígena $N^{\circ} 19.253$}

La Ley Indígena $\mathrm{N}^{\circ}$ 19.253, promulgada el 28 de septiembre de 1993, establece normas sobre reconocimiento, protección y desarrollo de las tierras indígenas. Además establece mecanismos y normas para propender al desarrollo indígena, consagra el reconocimiento, respeto y protección de las culturas e idiomas indígenas y, en su artículo 38, crea la Corporación Nacional de Desarrollo Indígena (CONADI) y, en su artículo 39, lo define como el organismo encargado de 
promover, coordinar y ejecutar, en su caso, la acción del Estado a favor del desarrollo integral de las personas y comunidades indígenas, especialmente en lo económico, social y cultural y de impulsar su participación en la vida nacional.

La ley define instrumentos específicos para cumplir con los objetivos señalados. El más conocido y más importante en términos presupuestarios como de impacto es el Fondo de Tierras y Aguas, creado por el artículo 20 de la ley, que tiene como rol específico fortalecer y ampliar el patrimonio indígena en lo referente a tierras, aguas e infraestructura de riego. A través de este Fondo, la CONADI podrá cumplir con los siguientes objetivos:

a) Otorgar subsidios para la adquisición de tierras por personas, comunidades indígenas o una parte de éstas cuando la superficie de las tierras de la respectiva comunidad sea insuficiente.

b) Financiar mecanismos que permitan solucionar los problemas de tierras, en especial, con motivo del cumplimiento de resoluciones o transacciones, judiciales o extrajudiciales, relativas a tierras indígenas en que existan soluciones sobre tierras indígenas o transferidas a los indígenas, provenientes de los títulos de merced o reconocidos por títulos de comisario u otras cesiones o asignaciones hechas por el Estado en favor de los indígenas. Este inciso es el más conocido y se ha popularizado su nombre como "tierras en conflicto", es el mecanismo al que más recursos financieros se han destinado.

c) Financiar la constitución, regularización o compra de derechos de aguas o financiar obras destinadas a obtener este recurso.

Particular impacto en La Araucanía -especialmente en el ámbito rural- ha tenido la Política de Tierras nacida a partir de la Ley Indígena $N^{\circ} 19.253$ ya que ha significado la compra y/o traspaso de más de 156.000 hectáreas, mayoritariamente

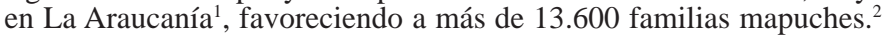

Esta política pública, que potencialmente tiene un gran impacto social, cultural y económico, ha visto disminuida su efectividad producto de una serie de cuestiones de carácter práctico y operativo.

En efecto, gran parte de los predios adquiridos no están contiguos a la comunidad original lo que dificulta su administración; por otra parte las tierras adquiridas tienen una organización y ordenamiento predial correspondiente a su función original, esto es, de explotaciones comerciales, lo que se traduce en falta de caminos interiores, escaso apotreramiento, insuficiente suministro de electricidad, agua potable y carencia de infraestructura productiva básica.

A lo anterior se agrega que, normalmente los nuevos habitantes han sido beneficiados con el subsidio habitacional en su comunidad de origen, por tanto no pueden volver a postular a este beneficio.

Carecer de vivienda y equipamiento determina que aquellos que deciden quedarse a vivir a pesar de las dificultades, lo hacen en condiciones muy precarias que atentan contra su calidad de vida y aquellos que no pueden quedarse, quedan imposibilitados de explotar su predio eficientemente y, por ende, obtener ingresos que lo hagan salir de su situación de pobreza. De hecho sólo el $40 \%$ de las familias beneficiadas hacen uso efectivo de los predios (Universidad de La Frontera 2011). 
Todo lo anterior da origen a una inserción extraordinariamente compleja e inestable de los campesinos en su nuevo predio. La situación descrita se traduce además, en la creciente demanda por apoyo social a las municipalidades de parte de los nuevos habitantes de sus comunas. Los recién llegados a la comuna obviamente demandarán servicios de salud, educación, pensiones asistenciales, asistencia técnica silvoagropecuaria, entre otras.

En el caso Fondo Nacional de Desarrollo Regional (FNDR) y de los recursos sectoriales, las tierras adquiridas requieren ser habilitadas, por tanto generan una gran demanda de inversión en caminos para comunidades (PDI), proyectos de agua potable rural (APR), abastos de agua, proyectos de electrificación rural (PER) y subsidio habitacional rural que sobrepasan largamente el presupuesto corriente del Gobierno Regional de La Araucanía, como de los sectores regionales. Un estudio reciente realizado por FAO el año 2011 a petición del Estado chileno, estimó en forma conservadora, una demanda insatisfecha de casi 800 millones de dólares de inversión en equipamiento para las tierras adquiridas y proyectadas a adquirir hasta el año 2018, en las regiones del Biobío, Araucanía, Los Ríos y Los Lagos. De ese monto, un 70\% corresponde a recursos requeridos en La Araucanía.

Permanece como una cuestión importante de dilucidar los efectos e impactos en la estructura social y cultural mapuche que la política de tierras podría originar al, por una parte, favorecer el traslado de comunidades a territorios distantes de su origen. Esto implica perder en gran medida patrones culturales asociados a identidades territoriales como la pewenche, lafkenche, nagche o wenteche. Las familias trasladadas no pueden continuar participando dentro de una lógica y estructura cultural específica similar, especialmente en los componentes de ritualidad, formas de vida y relación con los componentes naturales del espacio territorial.

Por otra parte, lleva también en parte a una recomposición organizacional y familiar, especialmente en los vínculos de parentesco patrilineal, elemento fundamental de la estructura de organización social mapuche. Del mismo modo, ello impone nuevos mecanismos de estructura económica-productiva y de economía cultural, ya que una relocalización conlleva a una nueva forma de establecer relaciones sociales y económicas en el marco de la cultura, la cual está fundada en el parentesco patrilineal, pero que ahora debe fundirse con la construcción de relaciones de reciprocidad e intercambio con otros troncos familiares distintos que no necesariamente obedecen a una misma lógica de funcionamiento (Universidad de La Frontera 2013).

Si consideramos que con la aplicación del artículo 20, letra b) de la Ley Indígena $\mathrm{N}^{\circ} 19.253$-que ha acumulado el $80 \%$ de los recursos del Fondo de Tierras- se pretende solucionar reivindicaciones de tierras y no aumento de la cabida de campesinos minifundistas -destino reservado al artículo 20, letra a)-, podemos especular que quizás un efecto importante, no buscado originalmente, sea el fortalecimiento del sector campesino mapuche puesto que los favorecidos con el Fondo de Tierras han pasado de manejar originalmente superficies aproximadas de 1.52 hectáreas a tener -después de la compra- en promedio 11.5 hectáreas, aumentando entonces entre 4,6 a 9,6 veces el tamaño de su superficie y patrimonio de tierras. Esto dentro del contexto de un proceso de modernización excluyente del agro que no privilegia en lo absoluto al sector campesino- resulta al menos un hallazgo muy particular. 


\section{La apertura económica y el cambio productivo}

A partir de la década de los ochenta en la Región de La Araucanía y en total coherencia con la nueva forma de organización mundial de la economía, se inicia un cambio económico productivo de mucha radicalidad. De ser una región agrícola cerealera -el granero de Chile- se empieza a transformar en una región forestal, básicamente apoyada en las plantaciones artificiales de pinos y eucaliptus, ambas especies exóticas (Henríquez 1988, 1989). De alguna manera esta región, que hace cien años fuera ocupada militarmente y taladas sus montañas para expandir la frontera agrícola chilena, volvió a recuperar su vocación primitiva.

En este escenario los cultivos agrícolas tradicionales pierden rentabilidad y para aquellos escasos suelos de mejor calidad y condiciones climáticas favorables que no pueden ser orientados a lo forestal, la alternativa es la agricultura de exportación en los rubros hortofrutícolas.

Una agricultura que de un contexto de economía protegida, en un corto lapso de tiempo pasa a enfrentar una apertura económica radical que genera grandes impactos en el sector, en particular en los cultivos tradicionales, base de la producción de la agricultura familiar, los que son reemplazados por las plantaciones forestales con especies exóticas-actividad fuertemente subsidiada por el Decreto $\mathrm{N}^{\circ} 701$ de fomento forestal- y en menor medida por cultivos orientados a la exportación.

Para tener una idea del cambio productivo señalado baste indicar que al alero del Decreto $N^{\circ} 701$ entre los años 1975 y 2011 se han plantado más de 630.000 hectáreas de pino (Pinus radiata) y eucaliptos (Eucaliptus globulos), esto es, a una tasa promedio cercana a las 17.200 hectáreas anuales, siendo el año 1979 el que presenta menor forestación con 6.436 hectáreas y el mayor el año 2005 con 43.060 hectáreas (Corporación Nacional Forestal 2012)

Este proceso de modernización económico productiva no ha sido capaz de resolver los problemas de equidad y, por el contrario, a menudo ha generado conflictos sociales y ambientales. En efecto, la transformación económica iniciada en los años ochenta solo significó progreso para aquellos espacios y grupos que lograron articularse a nuevos mercados, pero la lógica espacial del modelo generó nuevos desequilibrios intrarregionales. Esto ha dado lugar a crecientes diferencias territoriales donde existen “zonas ganadoras” compuestas por agrupaciones de comunas cuyo crecimiento económico, tasas inversión y empleo son notables, en tanto en otras el rezago es evidente. Estas diferencias obligan al Estado a desarrollar políticas y programas diferenciados para solucionar una gran cantidad de problemas muy diversos.

En efecto, con tal propósito, el Gobierno Regional de La Araucanía, ha zonificado el territorio regional, agrupando sus 32 comunas en 8 territorios de planificación, según su base física, tendencia al crecimiento o decrecimiento, su composición étnica o multicultural, los factores sociales incidentales en su desarrollo, red de centros urbanos, conectividad y su base económica, entre otros (Gobierno Regional de La Araucanía 2009).

El cambio económico productivo de agropecuario a forestal, además significó un grave problema económico para los campesinos, que tradicionalmente habían vendido su fuerza de trabajo a los fundos aledaños a sus predios. La actividad forestal tiene un patrón de empleo muy diferente a la agricultura, en concreto, las 
tareas se concentran en plantación, raleo, poda y cosecha, con intervalos de varios años entre estas faenas. Además, las grandes empresas forestales operan con subcontratistas, que se desplazan de faena en faena, entre comuna y regiones, y cuentan con empleados permanentes que trasladan a cada sitio de trabajo. Todo esto se traduce en pérdida de puestos de trabajo para la mano de obra local.

Esta pérdida de fuentes de trabajo se tradujo en una emigración constante desde aquellas comunas donde las plantaciones han sido mayores. Así, en las comunas del territorio denominado Nahuelbuta, compuesto por Los Sauces, Purén, Lumaco, Traiguen, Galvarino y Chol-Chol, entre los Censos de 1992 y 2002 vieron disminuir su población total en 5.000 personas, esto es, un $6,8 \%$. En tanto, la disminución de la población rural alcanzó al 15\% al comparar ambos censos.

En términos individuales resaltan los casos de Los Sauces, comuna que al comparar los Censos de Población y Vivienda de 1982 y 2002, ve disminuir su población rural en 30\%. Por su parte la comuna de Traiguén, en el mismo período, ve caer su población rural $29,7 \%$. Finalmente, el mayor dramatismo lo exhibe la comuna de Lumaco que entre el Censo de 1970 al 2002 vio disminuir su población rural en $47 \%$.

Para lograr un desarrollo forestal sustentable existen tres requisitos que la actividad forestal debiera cumplir para poder considerar a Chile un País Forestal (Donoso y Otero 2005) estos son:

1. Una gran parte de la población ve mejorada su calidad de vida a través de los bienes y servicios de los bosques.

2. Existe una institucionalidad fuerte, tanto público como privada, que resguarda el cumplimiento de normas modernas que regulen el buen manejo de bosques nativos y plantaciones.

3. Los bosques nativos y las plantaciones son cuidadosamente manejados, de modo de mejorar y conservar la biodiversidad, la productividad y los servicios ecosistémicos que éstos proveen.

Evidentemente, lo acontecido en Chile y en particular en La Araucanía con la explotación forestal, dista mucho de los parámetros fijados por los autores citados. Siendo evidente la necesidad de compartir sus conclusiones en el sentido que un desafío pendiente es conducir el modelo forestal chileno hacia mayores niveles de sustentabilidad, particularmente en lo ambiental y social.

Respecto del desempeño económico productivo, se constata en primer lugar que la producción regional vino creciendo a largo plazo, a un ritmo insuficiente para superar los bajos niveles socioeconómicos que la ubica, en general, entre las regiones del país con los menores indicadores en este sentido (Universidad Mayor 2008).

A ello se agrega la persistente presencia de una tasa de crecimiento inferior al promedio nacional prácticamente en todos los años posteriores a 1960, año en que se comienzan a registrar datos sobre el PIB regionalizado del país. Lo anterior, asociado al crecimiento de la población regional, ha conducido a la Región de La Araucanía a registrar el más bajo PIB por habitante entre las regiones del país en las últimas cinco décadas. 
Cabe señalar que esta situación contrasta con el potencial de diverso tipo con que cuenta la región, donde destacan sus recursos naturales. Estas características del crecimiento han limitado la creación de más oportunidades de empleo productivo y han ubicado a la región con el menor PIB por habitantes entre el conjunto de las regiones del país.

A lo anterior se debe señalar que, a pesar de la importante apertura externa del país, la región ha generado hasta ahora un muy pequeño volumen de exportaciones que la ubica en el año 2008 en el último lugar, en términos de valor de las mismas, a nivel nacional. Sin embargo, se debe destacar el caso de sectores emergentes como el de productos a base de cereales, leche, cremas, productos frutícolas, madera y manufactura de maderas.

Dentro de las características que acompañaron la evolución del proceso productivo de la Región de La Araucanía se destaca el hecho que ésta registró una muy baja absorción del total acumulado de la inversión extrajera materializada entre los años 1990 y 2007. La información existente al respecto ubica a la Región de La Araucanía entre la que menos inversión extranjera recibió en comparación con el resto de las regiones del país en el período mencionado. Cabe agregar que en el año 2008 no se registró este tipo de recurso en la región. La inversión pública que acompañó al proceso productivo de la región, a pesar de presentar niveles relativamente elevados, su tasa anual de crecimiento resultó ser de alrededor de tres veces inferior al promedio del país entre 1997 y 2007 (Universidad Mayor 2008).

Al tratar de explicar las causas del insuficiente desarrollo productivo de la Región de La Araucanía en las últimas décadas aparecen dos que se pueden calificar, en términos globales, como las de mayor relevancia en este proceso. La primera se refiere al grado de especialización que ha mantenido la región en sectores de lento crecimiento a nivel nacional. La segunda se vincula con el insuficiente grado de competitividad de los sectores mencionados anteriormente comparados con otros similares ubicados en otras regiones del país. En otras palabras, en lugar de atraer y desarrollar sectores modernos en su estructura económica, la región ha mantenido una participación relativa importante en sectores productivos tradicionales.

\section{Las transformaciones ambientales}

Por otra parte, este proceso de “reconversión productiva”, de lo agrícola a lo forestal, está provocando cambios ambientales, algunos manifiestamente negativos como, por ejemplo, acidificación del suelo, agotamiento de fuentes de aguas, disminución de la biodiversidad, utilización de suelos de aptitud agrícola-ganadero en actividades forestales, reemplazo de bosque nativo por plantaciones artificiales, otros de estos cambios ambientales por el contrario pueden ser considerados positivos, como por ejemplo la reforestación de suelos erosionados. Aunque respecto de esto último existen opiniones diversas (Montalba 2004).

Al respecto, la Corporación Nacional Forestal (2009) señala que entre los años 1993 y 2007 en La Araucanía los cambios absolutos y porcentuales en el uso del suelo son los siguientes: la mayor caída la presentan los Terrenos Agrícolas (-) 116.829 hectáreas correspondiente a una disminución de 12,5\%, seguido por Praderas y Matorrales con (-) 63.467,4 hectáreas, correspondiente a una caída de $9,4 \%$. 
En valor absoluto, el mayor aumento de superficie afectó al uso Bosques con 179.440,1 hectáreas, esto es, un aumento del 13,1\%. Sin embargo, dentro del uso Bosques, el mayor aumento lo presenta el subuso Plantaciones con un crecimiento de 220.854,1 hectáreas, equivalente al 62,9\%; mientras que el subuso Bosque Nativo presenta una disminución de 39.827,3 hectáreas, es decir, cae en 4,1\%. El mismo estudio indica que existe una dinámica de conversión de terrenos agrícolas hacia bosques plantados o plantaciones, resultados coherentes con los resultados del VII Censo Agropecuario y Forestal de 2007.

Por otra parte, el Bosque Nativo presenta una pérdida de -39.827,3 hectáreas $(-4,1 \%)$. Desde una perspectiva territorial la mayor disminución de la superficie cubierta con bosque nativo ocurrió en la provincia de Malleco (24.275,8 hectáreas). La explicación para esta pérdida de bosque nativo es que se origina producto del traspaso de superficies a plantaciones (29.636,1 hectáreas) y a praderas y matorrales (16.454,1 hectáreas) principalmente.

Este cambio sostenido, ha traído también modificaciones en el ciclo hidrológico, generando escasez de aguas superficiales en las comunidades vecinas, disminución de la biodiversidad y aumento de la erosión, cuando se procede a la cosecha de los bosques artificiales. Esto, porque el proceso se realiza a tala raza, dejando el suelo desnudo y desprotegido frente a las lluvias. Todos estos cambios y la negativa opinión respecto de esta actividad económica por parte de las comunidades locales, en particular de la población mapuche, ha sido reportado en repetidas ocasiones (Montalba 2005). Estos cambios ambientales originados en las plantaciones son parte de las reclamaciones más enérgicas de las comunidades mapuches.

Tratando de ahondar en los elementos culturales que subyacen en este malestar expresado por las comunidades mapuches en contra de las plantaciones forestales, podemos decir que sabemos que la naturaleza no se muestra al hombre en forma estática, de una vez y para siempre. La relación humana con la naturaleza es paulatina. El conocer cada uno de los recursos que tiene y el uso que puede hacerse de ellos, es un proceso que lleva generaciones. La cultura mapuche no es una excepción en esta forma de apropiación de la naturaleza y sus recursos (Henríquez 2003).

A su vez, en las estrategias productivas que los pueblos eligen intervienen no solo criterios técnicos, sino también culturales, económicos, políticos, ideológicos y religiosos. Este tipo de representaciones otorgan sentido a las conductas y acciones sobre la naturaleza que muchas veces pueden llegar a aparecer irracionales a los ojos occidentales. Todos estos elementos contribuyen a constituir el "corpus de conocimiento campesino” (Baraona 1994).

La radicación y reducción del pueblo mapuche, por su magnitud y velocidad, no solo significó un grave daño económico y alteración de su estructura social, también significó una grave agresión al corpus de conocimiento mapuche que debió ser actualizado mediante un trabajoso proceso adaptación y aprendizaje.

La radicalidad del cambio productivo en curso -de agrícola a forestal- ha puesto en juego una relación trabajosamente construida durante el siglo XIX y XX entre naturaleza y pueblo mapuche. Al respecto podemos señalar que la escasez de agua de la cual responsabilizan a las plantaciones forestales artificiales no es solo un tema de sequía estacional o de impactos ambientales, sino de una alteración profunda de la relación cultura mapuche y naturaleza (Henríquez 2003). 
Respecto de qué responsabilidad le cabe a la sociedad y al Estado en minimizar este tipo de daños y complementariamente como apoyar procesos de reconstrucción de conocimiento por parte de la población mapuche rural hay poca reflexión y propuestas.

\section{La calidad de vida y pobreza rural}

A partir de la re-democratización del país, sus regiones y municipios se vieron incrementados el establecimiento de programas sociales e inversiones en infraestructura social y económica que se han traducido en innegables progresos para La Araucanía y sus habitantes rurales. Así, es posible constatar que en la actualidad el 96\% de la población rural tiene energía eléctrica en sus hogares, la totalidad de las ciudades cabeceras comunales tienen acceso mediante camino pavimentado y la pobreza rural cayó de un 45.4\% el año 1990 a un 19,9\% el 2006.

Los datos socioeconómicos de la región permiten una aproximación a su perfil social a partir de distintas dimensiones, entre ellas, la educacional, los ingresos autónomos, la habitabilidad y el acceso a servicios, entre otros.

Con relación al nivel de alfabetización, las cifras evidencian las brechas entre el mundo rural y el urbano. En este aspecto, a nivel urbano un 2,5\% de la población regional es analfabeta y a nivel rural, un 8,8\%. En este contexto, es destacable que a nivel regional se observe una tendencia a la reducción del número de analfabetos, tanto en zona urbana como en zona rural, pero con una mayor intensidad en la zona urbana. En este caso pueden coexistir elementos de mejor acceso a servicios de infraestructura, transporte e inversión pública educacional que implican una mejoría en este indicador (Agraria Sur 2013).

En la misma línea anterior, la escolaridad promedio en el periodo 2011 es de 10,16 años en el sector urbano regional y 7,15 años en el mundo rural. Sin embargo, es en este sector, en el periodo 2006-2009, donde la escolaridad promedio aumenta. Las explicaciones o hipótesis podrían estar en la misma dirección de la variable anterior, en el sentido que el mejoramiento de políticas públicas y su focalización y los incrementos de servicios en general, podrían gatillar estos mejoramientos.

Desde el punto de vista del acceso a los servicios de infraestructura, la cobertura de agua potable es casi $100 \%$ en la región a nivel urbano. Indudablemente el crecimiento en inversión y la modernización de los servicios se ve reflejado en las cifras. Sin embargo, en el mundo rural la situación es distinta. Es así como, por ejemplo, en las comunas de Malleco Norte sólo el 15\% de las viviendas posee acceso a agua potable (Ibíd.).

En el resto de las comunas ha aumentado de manera importante el acceso al agua a través de camiones aljibe dada la compleja situación producida por la sequía en los últimos años. Resulta preocupante que existan comunas en las que sus habitantes rurales deben ser abastecidos con agua durante todo el año.

En la misma dirección, el acceso a sistemas de eliminación de excretas a nivel urbano en la región es de un 98\% de las viviendas. A nivel rural sólo el 43\% de las viviendas dispone de alcantarillado o fosa séptica, el 56\% dispone de letrina o cajones. Ejemplo de esto es el territorio de Nahuelbuta, que cuenta solo con un $23 \%$ de acceso a un sistema de saneamiento, esto es, alcantarillado o fosa séptica. 


\section{Conclusiones}

Concluyendo, podemos señalar que desde la perspectiva del desarrollo sustentable, las transformaciones que han afectado a la ruralidad de La Araucanía han tenido un resultado muy magro, ya que si bien es cierto han mejorado las condiciones de vida en los espacios rurales y también existido una disminución de la pobreza, ésta sigue siendo una de las más alta del país.

Por otra parte, la falta de cohesión social originada en la marginación, discriminación y exclusión social ha sido una constante de largo tiempo en La Araucanía rural y, como hemos visto en esta apretada revisión, a menudo las políticas públicas lejos de constituirse en "un proceso que vincule causalmente los mecanismos de integración y bienestar con la plena pertenencia social de los individuos” (CEPAL 2007), han operado en sentido inverso.

La economía de La Araucanía, su crecimiento y diversificación en el futuro mediato, aparentemente seguirá vinculada a los recursos naturales y, consecuentemente, a la ruralidad. Es lo que nos indica el crecimiento experimentado en los últimos años por las inversiones en los sectores turismo, acuicultura y energía basada en recursos renovables no convencionales. Esto significa que la superación del modelo de uso de los recursos naturales renovables ejecutado hasta la hora es un desafío ineludible y condición no sólo para mejorar los ingresos y condiciones de vida de las familias rurales, sino que también para alcanzar la paz social.

Al respecto, la reciente aprobación por parte de UNESCO de la ampliación de la reserva de la Biosfera Araucarias -con una superficie de 1.400.000 hectáreas, equivalente a alrededor del 36\% de la superficie total de la región- abre una oportunidad de establecer políticas públicas de desarrollo sustentable que puedan contribuir a superar las brechas que presenta la ruralidad de La Araucanía.

El continuar con modelos y políticas disfuncionales -como ha sido hasta la actualidad- desafortunadamente nos hacen augurar la repetición de hechos de violencia que han costado la vida de mapuches y no mapuches en el último tiempo en esta cambiante Araucanía rural. 


\section{Notas}

${ }^{1}$ Se han realizado compras de tierras a comunidades de La Araucanía en que el predio adquirido está ubicado en regiones vecinas.

${ }^{2}$ CONADI, Subdirección Nacional Sur, comunicación personal. Incluye compras letras a y b del artículo 20 de la Ley Indígena $N^{\circ} 19.253$, además de traspaso de predios fiscales. 


\section{Bibliografía}

Agraria Sur (2013), Componente Rural del Plan Regional de Ordenamiento Territorial de La Araucanía. Temuco.

Aylwin, J. y Castillo, E. (1990), “Legislación sobre indígenas en Chile a través de la historia”. Documento de Trabajo $N^{o} 3$. Programa de Derechos Humanos y Pueblos Indígenas, Comisión Chilena de Derechos Humanos. Santiago, Chile.

Baraona, Rafael (1987), Conocimiento campesino y sujeto social campesino. PIEE, Santiago, Chile.

Bauer, A. J. (1994), La sociedad rural chilena. Desde la conquista española a nuestros días. Editorial Andrés Bello, Santiago, Chile.

Berdichewsky, B. (1983), "El pueblo araucano y su lucha por la sobrevivencia”, Anthropologica, Vol. 1. $N^{\circ} 1$, pp. 239-290.

CEPAL (2007), Cohesión Social Inclusión y sentido de pertenencia en América Latina y el Caribe. Santiago.

Correa, M; Molina, R; Yáñez, N. (2005), La reforma agraria y las tierras mapuches, Chile 1961-1975. LOM Ediciones. Santiago, Chile.

Corporación Nacional Forestal (2009), Catastro de uso de suelo y vegetación, período 1993-2007. Monitoreo y actualización Región de La Araucanía. Ministerio de Agricultura, Santiago, Chile.

Corporación Nacional Forestal (2012), Estadísticas Forestales. Superficie de plantaciones forestales (forestación y reforestación), por Región y año (ha). En http://www.conaf.cl/bosques/seccion-estadisticas-forestales.html

Centro de Estudios Sociales, (2001), Muerte y desaparición forzada en la Araucanía: una aproximación étnica. Ediciones de la Universidad Católica de Temuco.

Centro EULA (2003), Ampliación y sistematización de la información diagnóstica de los litigios de tierras indígenas en la Región de la Araucanía, originados en el proceso de reforma agraria entre los años 1960 y 1980. Universidad de Concepción, Chile. Realizado para Corporación Nacional de Desarrollo Indígena.

Donoso, Pablo J y Otero, Luis A. (2005), "Hacia una definición de país forestal: ¿Dónde se sitúa Chile?”. Bosque (Valdivia), Vol. 26, № 3, pp. 5-18.

FAO (2012), Perfil de Programa para la Atención Integral de Familias de Comunidades Indígenas con Predios Adquiridos. Programa Fortalecimiento de las Capacidades Nacionales para la Prevención y Gestión de Conflictos 
Interculturales en Chile, Santiago, Chile.

Flores, Jaime (2006), “Economías locales y mercado regional. La Araucanía 1883-1935”, Espacio Regional. Revista de Estudios Sociales, Vol. 2, № 3. Universidad de Los Lagos, Osorno.

Garrido José, Guerrero Cristián y María S. Valdez (1988), Historia de la reforma agraria en Chile, Editorial Universitaria, Santiago, Chile.

Gobierno Regional de La Araucanía (2009), Diagnóstico Regional. Herramienta para el Desarrollo, Modelo de Gestión Territorial, Temuco, Chile.

Henríquez, Luis (1988), Informe de coyuntura agraria $N^{\circ} 1$, IX Región, Grupo de Investigaciones Agrarias, Academia de Humanismo Cristiano, Santiago, Chile.

Ídem (1989), Informe de coyuntura agraria $N^{o} 2$, IX Región. Grupo de Investigaciones Agrarias, Academia de Humanismo Cristiano. Santiago, Chile.

Ídem (2003), "Evolución del conocimiento campesino forestal mapuche”. En Árboles, Recursos Naturales y Comunidades Indígenas en Chile. Corporación Nacional Forestal, Santiago, Chile.

Huenchumilla, Francisco (2002), "Estado de derecho se burla del mapuche”, entrevista en revista Punto Final, $N^{\circ}$ 517, abril 2002. http;// www.puntofinal.cl/

Kay, Cristóbal (1995), “Desarrollo rural y cuestiones agrarias en la América Latina contemporánea”, Agricultura y Sociedad, N 75 . Ministerio de Agricultura, Pesca y Alimentación. España.

Montalba, R. (2005), “Desarrollo Sostenible o Eco-Etnocidio?: El Proceso de Expansión Forestal en Territorio Mapuche-Nalche de Chile” AGER, Número 4 .Revista de estudios sobre despoblamiento y desarrollo rural. Centro de Estudios sobre la Despoblación y Desarrollo de Áreas Rurales. Zaragoza, España.

Ídem (2004), “Transformación de los agroecosistemas y degradación de los recursos naturales en el territorio mapuche: una aproximación historicoecológica”, Revista CUHSO, Vol. 8, Universidad Católica de Temuco.

Pinto, J. y Ordenes, M. (2012), Chile una Economía Regional. La Araucanía 1900-1960. Ediciones de Universidad de la Frontera, Temuco.

Rivera, R. (1988), Los campesinos chilenos. Grupo de Investigaciones Agraria. Academia de Humanismo Cristiano. Santiago, Chile. 
Universidad de La Frontera (2011), Estudio Evaluación socioproductiva de las tierras adquiridas por el Fondo de Tierras y Aguas Indígenas de CONADI. Instituto del Medio Ambiente. Universidad de La Frontera. Temuco, Chile. Estudio realizado para CONADI.

Ídem (2013), Estudio Modelo de Integración de Instrumentos de Planificación Regional y Local. Instituto de Desarrollo Regional y Centro de Investigaciones Territoriales, Universidad de La Frontera. Temuco, Chile. Estudio realizado para Gobierno Regional de La Araucanía.

Universidad Mayor (2010), Informe $N^{o} 4$ Diagnóstico Regional. DesarroIlo Económico y Competitividad. Estrategia Regional de Desarrollo de La Araucanía, 2010-2022. Temuco, Chile. Estudio realizado para Gobierno Regional de La Araucanía.

Zúñiga, Carlos (1997), El texto público como elemento de la construcción del imaginario colectivo. La percepción del "Cautinazo" a través de la prensa local. Tesis de Maestría en Ciencias Sociales Aplicadas. Universidad de La Frontera. Temuco.

Recibido: 15.02.2013

Aceptado: 07.03.2013 